\title{
Phonological and Metrical Variation across Genres
}

\author{
Arto Anttila and Ryan Heuser \\ Stanford University
}

\section{The question}

In his introduction to meter and versification, Timothy Steele writes:

\begin{abstract}
"Would that poets had a prosodic device, analogous to a voltage tester or a circuit analyzer, to enable them to assess the current in a doubtful line. But though an optimistic novice might fancy that determinations could be made merely by checking where stresses fall - and that trouble is signaled when a beat lands on an odd-numbered position or an off-beat lands on an even-numbered position - matters are not so simple." (Steele 1999, 156)
\end{abstract}

The question of how to distinguish a metrical line from an unmetrical line is at the heart of the study of metrics. Closely related and no less interesting is the question of how to distinguish a line of metered verse from a line of unmetered prose. To get a sense of the problem, consider the following random five-word text fragments organized into two columns. One column is verse, the other column is prose. The task is to determine which is which.

$$
\begin{aligned}
& \text { mankind do know of hell } \\
& \text { fled away into the storm } \\
& \text { the castle or the cot } \\
& \text { her vespers done of all } \\
& \text { a richness that the cloudy } \\
& \text { fix'd as in poetic sleep } \\
& \text { cold fair isabel poor simple } \\
& \text { little cottage i have found } \\
& \text { last prayer if one of } \\
& \text { one hour half-idiot he stands }
\end{aligned}
$$

\author{
readiness to measure time by \\ in a trio while $\mathrm{i}$ \\ your sisters severally to george \\ the weather is unfavourable for \\ be in time perhaps it \\ i shall horribly commit myself \\ as bad again just now \\ i shall have got some \\ bless you sunday evening my \\ bars at charles the first
}

Both columns were extracted from the works of John Keats. The fragments on the left are verse; the fragments on the right are prose. Distinguishing prose from verse no doubt involves many factors, including typography, vocabulary, parallelism, and rhyme. In the present study, we set ourselves the goal of understanding to what extent basic phonological notions can help classify a fragment of text as metered verse or unmetered prose. In some cases the role of phonology is fairly obvious. To continue with one of Steele's examples, it is not hard to hear that the ten-syllable sentence I can't believe that I forgot my keys works well as a line of iambic pentameter, whereas another ten-syllable sentence It rains almost always when I visit does not. This judgment likely has something to do with the distribution of word stresses in these sentences, as can be seen from the scansions in (2).

\footnotetext{
* This work has benefited from presentations at the Stanford Phonology Workshop (October 2, 2015), the 2015 Annual Meeting on Phonology in Vancouver, BC (October 11, 2015), and the Boston University Linguistics Colloquium (February 12, 2016). We are deeply indebted to Josh Falk for his contributions to the Prosodic project. We also thank Jon Barnes, Jared Bernstein, Lev Blumenfeld, Joan Bresnan, Charles Chang, Daniel Erker, Vivienne Fong, Paul Kiparsky, Will Leben, Carol Neidle, Stephanie Shaw, Stephanie Shih, Peter Staroverov, and Simon Todd for their input. The financial help of the Hellman Junior Faculty Scholar Fund and the Office of the Vice Provost for Undergraduate Education (VPUE) at Stanford University is gratefully acknowledged. We are responsible for any errors.
}

(C) 2016 Arto Anttila and Ryan Heuser

Proceedings of AMP 2015

Completed April 4, 2016 
(a)

$\left(\begin{array}{llll}\mathrm{w} & \mathrm{s}\end{array}\right)\left(\begin{array}{ll}\mathrm{w} & \mathrm{s}\end{array}\right)\left(\begin{array}{ll}\mathrm{w} & \mathrm{s}\end{array}\right)\left(\begin{array}{lll}\mathrm{w} & \mathrm{s}\end{array}\right)\left(\begin{array}{ll}\mathrm{w} & \mathrm{s}\end{array}\right)$

$\begin{array}{lll} & \text { s } & \text { W } \\ + \text { stress } & 4 & 0 \\ \text { - stress } & 1 & 5\end{array}$

(b)

$\left(\begin{array}{lll}w & \text { s}\end{array}\right)\left(\begin{array}{lll}w & \text { s}\end{array}\right)\left(\begin{array}{lll}w & \text { s}\end{array}\right)\left(\begin{array}{ll}w & \text { s}\end{array}\right)\left(\begin{array}{ll}w \\ \text { s }\end{array}\right)$

It ráins álmost álways whén I vísit

$\begin{array}{lll} & \text { S } & \text { W } \\ + \text { stress } & 1 & 4 \\ - \text { stress } & 4 & 1\end{array}$

The Steele quote suggests that in stress-based meters stressed syllables tend to avoid weak metrical positions and unstressed syllables tend to avoid strong metrical positions. This means that we may be able to use the degree of alignment between strong vs. weak positions and stressed vs. unstressed syllables as a crude first approximation of the metricality of a scansion. In (2a) all syllables with primary stress are neatly aligned with strong positions and all other syllables are almost as neatly aligned with weak positions except for the pronoun $I$ which is arguably lexically unstressed. In the second example the alignment pattern is nearly reversed. This accounts for the judgment that (2a) works well as a line of iambic pentameter whereas $(2 b)$ does not. The view implicit in this illustrative example is that metricality has to do with the CORRESPONDENCE between metrical positions (s, w) and their phonological realizations; see, e.g., Kiparsky 1977; Prince 1989; Hanson and Kiparsky 1996; Hayes, Wilson and Shisko 2012; and Blumenfeld 2015. Golston 1998 and Golston and Riad 2000, 2005 present an alternative view.

In this paper, we report on a preliminary study where we contrasted the phonological and metrical properties of prose and verse in the works of five English-language and five Finnish-language authors based on material available on Project Gutenberg (gutenberg.org) and Literature Online (literature.proquest.com). The authors are Keats, Shelley, Whitman, Wordsworth, and Yeats (English) and Erkko, Kaatra, Leino, Lönnrot, and Siljo (Finnish). All these authors wrote prose as well as verse. After pre-processing the texts, ${ }^{1}$ we divided them into fragments in which each fragment has exactly five words, with no punctuation, in order to guarantee that any phonological or metrical difference between prose and verse that might emerge would have nothing to do with line length, but only with the local phonological and metrical arrangement of words. Our dataset consists of 500 randomly sampled fragments for each author-genre pair, yielding 10,000 fragments in all. Our main goal was to find out whether phonological and metrical constraints independently proposed by phonologists and metricists can reliably identify arbitrary lines of text as metered verse vs. unmetered prose.

\section{Constraints}

We first need to select some phonological and metrical properties that seem to be involved in distinguishing prose and verse. We conceptualize such properties as CONSTRAINTS that can be VIOLATED by particular texts or particular scansions (Prince and Smolensky 1993/2004). A phonological constraint can be violated by a piece of text, such as a syllable or a pair of syllables; a metrical constraint can be violated by a scansion, i.e., a pairing of a metrical position and a piece of text. On the phonological side, we adopted the constraints in (3), see, e.g., Prince 1990 and Prince and Smolensky 1993/2004:
(a) PEAKPROM
'No stressed light syllables' (= Peak Prominence)
(b) WSP
(c) NOCLASH
'No unstressed heavy syllables' (= The Weight-to-Stress Principle)
(d) NOLAPSE
'No adjacent stressed syllables'
'No adjacent unstressed syllables'

On the metrical side, we adopted four constraints from the work of Hanson and Kiparsky (1996), henceforth $\mathrm{H} \& \mathrm{~K} .{ }^{2}$ The constraints in (4) will turn out to be central; the remaining two will be introduced shortly.

\footnotetext{
${ }^{1}$ Texts from Literature Online were converted from SGML into plain-text files; texts from Project Gutenberg were downloaded in plain-text form. All plain-text files were then cleaned by removing headers, footers, and tables of content; titles to poems or chapters; and in-set poems from the prose texts.

${ }^{2}$ We have taken the liberty of renaming H\&K's constraints in the interest of transparency.
} 

(a) *S/UNSTRESSED 'A strong position may not contain an unstressed syllable'

(b) *W/PEAK 'A weak position may not contain a peak'

A PEAK is defined as the head of a branching constituent, roughly, the main stress of a polysyllable; a TROUGH is defined as a non-head of the same. Thus, the words mány and réptile have the structure peak + trough and the words imménse and màintáin have the structure trough + peak. The monosyllabic word kéen is neither a peak nor a trough. ${ }^{3}$ To illustrate the constraint *W/PEAK consider the examples in (5). In canonical English verse violations of this constraint are routine in the first foot (inversion) and sometimes occur after major syntactic breaks within the line, but are avoided elsewhere.

(5)

$$
\left(\begin{array}{ll}
\mathrm{W} & \mathrm{s}
\end{array}\right)\left(\begin{array}{lll}
\mathrm{W} & \mathrm{s}
\end{array}\right)\left(\begin{array}{ll}
\mathrm{W} & \mathrm{s}
\end{array}\right)\left(\begin{array}{ll}
\mathrm{W} & \mathrm{s}
\end{array}\right)\left(\begin{array}{ll}
\mathrm{W} & \mathrm{s}
\end{array}\right)
$$$$
\text { Néver cáme póison fróm só swéet a place }
$$

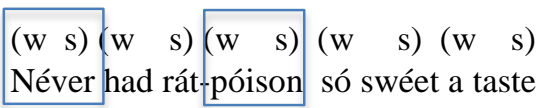

Number of $*$ W/PEAK violations

$1 \quad$ (Richard III.1.2)

2 (construct)

According to $\mathrm{H} \& \mathrm{~K}$, mainstream English and Finnish meters differ crucially with respect to these two constraints (H\&K, pp. 287-8): Shakespeare's iambic pentameter avoids violations of *W/PEAK; Finnish iambic-anapestic (trochaic-dactylic) meters avoid violations of *S/UNSTRESSED. One of our goals was to test the empirical validity of this generalization against a representative sample of data from both languages.

\section{Method}

In order to determine whether prose and verse differ objectively in terms of our constraints it is necessary to annotate the texts phonologically and metrically. Instead of hand-annotation (see, e.g., Hayes, Wilson, and Shisko 2012) we used PROSODIC (Heuser, Falk, and Anttila 2010), a software package for the phonological analysis and metrical scansion of texts. The obvious advantage of machine analysis is that it is cheaper and faster than hand-annotation and opens up much larger datasets. In our study, the crucial advantage is that Prosodic is able to scan prose as well as verse. It simply does not know the difference. This would seem to be quite impossible for humans: one can hire experienced readers to scan metered verse, but asking them to scan unmetered prose would hardly make sense, especially if we want them to apply exactly the same principles of scansion to both-yet that is precisely what we need to do. This leaves machine analysis as the only viable option. While less accurate than hand-coding, the results of our current machine analysis seem to provide a reasonable baseline that is useful for phonological and metrical research.

The input to Prosodic consists of plain text and constraints parametrized by the user. The output is the same text enriched by phonological and metrical information, including word stress, syllable structure, possible metrical scansions, and for each scansion, the violation count for each constraint.

The phonological analysis of English builds on the CMU Dictionary (Weide 1998) and OpenMary (mary.dfki.de). The phonological analysis of Finnish is done from scratch by a Prosodic module written by Josh Falk based on the rules in Karlsson $(1982,1985)$. Sample annotations are shown in (6). The first column shows the word as it occurs in the text; the second column is the phonological transcription; the third column shows the word stress profile ( $\mathrm{P}=$ primary stress, $\mathrm{S}=$ secondary stress, $\mathrm{U}=$ unstressed $)$; and the fourth column shows the syllable weight profile $(\mathrm{H}=$ heavy, $\mathrm{L}=$ light $)$.

(a)

$$
\text { i }
$$

shall

horribly

commit

myself
P:'ai

P:'‘æl

P:'ho:.rə.bli:

P:kə.'mit

P:`mar.'self
S:P

S:P

S:PUU

S:UP

S:SP
W:H

W:H

W:HLH

W:LH

W:HH

\footnotetext{
${ }^{3}$ The reason for referring to peaks and troughs instead of just stressed and unstressed syllables has to do with the special role monosyllabic words play in verse (see, e.g., Hanson and Kiparsky 1996).
} 
(b)

$\begin{array}{llll}\text { kellon } & \text { P:'kel.lon } & \text { S:PU } & \text { W:HH } \\ \text { avutonta } & \text { P:'a.vu.`ton.ta } & \text { S:PUSU } & \text { W:LLHL } \\ \text { ontuvaa } & \text { P:'on.tu.vaa } & \text { S:PUU } & \text { W:HLH } \\ \text { naksutusta } & \text { P:'nak.su.'tus.ta } & \text { S:PUSU } & \text { W:HLHL } \\ \text { ei } & \text { P:'ei } & \text { S:P } & \text { W:H }\end{array}$

Prosodic does metrical scansion by starting from all the s/w scansions possible for a line of input. For example, given a line of 10 syllables the upper bound is $2^{10}=1,024$ scansions. Prosodic assigns each scansion a constraint violation vector, discards the harmonically bounded scansions (for the notion of harmonic bounding, see, e.g., McCarthy 2008:80-83), and returns the remaining scansions with a violation count for each constraint. ${ }^{4}$ A central problem in the prosodic parsing of English is the stress ambiguity of monosyllabic function words. For example, the indefinite article $a$ may be either the lexically unstressed /ə/ or the lexically stressed /eI/. This kind of ambiguity is pervasive in English and arises with most monosyllabic function words. For example, in the sentence I live in this house the preposition in tends to be unstressed, whereas in the sentence I won't give in the particle in tends to be stressed. One possible analysis is that the preposition is lexically unstressed whereas the particle is lexically stressed, but in the absence of a syntactic parse we cannot tell which reading is intended. Prosodic deals with such cases by identifying the relevant words based on word lists (unstressed words, stress-ambiguous words, stressed words) and by considering both readings. The ambiguity is later resolved as part of the scansion.

The resulting constraint violation vectors are our data. They contain rich information about the phonological and metrical differences among the input lines and thus provide a window into the differences between prose and verse.

\section{Examples}

We illustrate metrical scansion in terms of the four metrical constraints in (7) adopted from H\&K. According to $\mathrm{H} \& \mathrm{~K},(7 \mathrm{a})$ and (7d) are central for distinguishing mainstream English and Finnish meters.
(a) *S/UNSTRESSED 'A strong position may not contain an unstressed syllable'
(b) *S/TROUGH 'A strong position may not contain a trough'
(c) *W/STRESSED 'A weak position may not contain a stressed syllable'
(d) *W/PEAK 'A weak position may not contain a peak'

4.1 Verse We start our illustration by scanning the line Never came poison from so sweet a place. For the moment, let us assume that each metrical position must be occupied by a single syllable. In this example only the iambic scansion is possible. The syllables in strong metrical positions are capitalized. The constraints violated by a particular syllable are shown on its right.

\begin{tabular}{llll}
\multicolumn{4}{l}{ [parse \#1 of 1]: 5 errors } \\
1 & w & ne & *W/PEAK, *W/STRESSED \\
2 & s & VER & *S/UNSTRESSED, *S/TROUGH \\
3 & w & came & $*$ W/STRESSED \\
4 & s & POI & \\
5 & w & Son & \\
6 & s & FROM & \\
7 & w & So & \\
8 & s & SWEET \\
9 & w & a & \\
10 & S & PLACE
\end{tabular}

\footnotetext{
${ }^{4}$ For this experiment, harmonic bounding was performed including only the four metrical constraints listed in (7). Subsequently, all constraint violations - including those in (3) - were computed and averaged across all nonharmonically-bounded parses to produce, for each constraint, a mean violation score for the fragment of prose or verse as a whole.
} 
Next, consider the line Never had rat-poison so sweet a taste. This time, both the trochaic scansion and the iambic scansion are possible, but the trochaic scansion has fewer violations. ${ }^{5}$

\begin{tabular}{llll}
\multicolumn{4}{l}{ [parse $\#$ 1 of 2]: 5 errors } \\
1 & s & NE & \\
2 & w & ver & \\
3 & s & HAD & $*$ S/UNSTRESSED \\
4 & w & rat & *W/STRESSED \\
5 & s & POI & \\
6 & w & son & \\
7 & s & SO & *S/UNSTRESSED \\
8 & w & sweet & $*$ W/STRESSED \\
9 & s & A & \\
10 & w & taste &
\end{tabular}

(10)

\begin{tabular}{llll}
\multicolumn{2}{l}{ [parse \#2 of 2]: 8 errors } & \\
1 & w & ne & $*$ W/PEAK *W/STRESSED \\
2 & s & VER & $*$ S/UNSTRESSED, *S/TROUGH \\
3 & w & had & \\
4 & s & RAT & \\
5 & w & poi & $*$ W/PEAK, *W/STRESSED, \\
6 & s & SON & $*$ S/UNSTRESSED, *S/TROUGH \\
7 & w & So & \\
8 & s & SWEET & \\
9 & w & a & \\
10 & s & TASTE &
\end{tabular}

This example illustrates how Prosodic resolves stress ambiguity in monosyllabic function words as part of the scansion. The relevant word is $a$. Under the trochaic parse $a$ ends up in a strong position and Prosodic selects the stressed $a=/ \mathrm{eI} /$. Selecting the unstressed $a=/ \mathrm{\partial} /$ gratuitously violates *S/UNSTRESSED and results in a harmonically bounded scansion. Under the iambic parse $a$ ends up in a weak position and Prosodic selects the unstressed $a=/ \partial /$. Selecting the stressed $a=/ \mathrm{eI} /$ gratuitously violates $* \mathrm{~W} / \mathrm{STRESSED}$ and results in a harmonically bounded scansion.

Next consider the familiar line To be or not to be that is the question. Under the requirement that each metrical position must be occupied by a single syllable Prosodic only delivers the iambic scansion.

\begin{tabular}{llll}
\multicolumn{5}{l}{ parse $\#$ 1 of 1]: 3 errors } \\
1 & w & to & \\
2 & s & BE & *S/UNSTRESSED \\
3 & w & or & \\
4 & s & NOT & \\
5 & w & to & \\
6 & s & BE & *S/UNSTRESSED \\
7 & w & that & \\
8 & s & IS & *S/UNSTRESSED \\
9 & w & the & \\
10 & s & QUE & \\
11 & w & stion
\end{tabular}

Native speakers sometimes experience individual lines as fitting more than one meter. In addition to the iambic pentameter scansion this line also easily scans as dactylic tetrameter (Blumenfeld 2015, 84). If we

\footnotetext{
${ }^{5}$ Prosodic allows the user to weight individual constraints differently, but we have not made use of that option here.
} 
relax the meter by allowing a weak position to contain up to two syllables (i.e., resolution, Kiparsky 1989) we get the dactylic scansion as well. ${ }^{6}$

$\begin{array}{lll}\text { [parse \#1 of 2]: } & 1 \text { errors } \\ 1 & \text { s } & \text { TO } \\ 2 & \text { w } & \text { be or } \\ 3 & \text { s } & \text { NOT } \\ 4 & \text { w } & \text { to be } \\ 5 & \text { s } & \text { THAT } \\ 6 & \text { w } & \text { is the } \\ 7 & \text { S } & \text { QUE } \\ 8 & \text { w } & \text { stion }\end{array}$

4.2 Prose The key advantage of Prosodic is that it blindly analyses any text, metered verse as well as unmetered prose. This is crucial if we want to compare verse and prose. The constraint violation vectors produced by the machine analysis contain rich information about the phonological and metrical properties of input lines and thus allow us to explicitly compare lines of prose to lines of verse.

What should we expect to find? Perhaps we can expect verse to have fewer constraint violations than prose across the board. After all, poetry is sometimes defined as the best words in the best order. This turns out to be true for some constraints, but not for others. It would also not be surprising to find that prose occasionally scans like metered verse. This can be illustrated by the following sentence from Franklin D. Roosevelt's first inaugural address which scans as iambs with no violations:

$\begin{array}{lll}1 & \text { w } & \text { the } \\ 2 & \text { s } & \text { ONL } \\ 3 & \text { w } & \text { y } \\ 4 & \text { s } & \text { THING } \\ 5 & \text { w } & \text { we } \\ 6 & \text { s } & \text { HAVE } \\ 7 & \text { w } & \text { to } \\ 8 & \text { s } & \text { FEAR } \\ 9 & \text { w } & \text { is } \\ 10 & \text { s } & \text { FEAR } \\ 11 & \text { w } & \text { its } \\ 12 & \text { s } & \text { ELF }\end{array}$

The effect is probably intentional. ${ }^{7}$ Note that the syntactic variant Fear itself is the only thing we have to fear (construct) is metrically worse: parsed iambically, Fear it / self is / incurs six constraint violations: *W/STRESSED (2 violations, fear, -self), *S/UNSTRESSED (2 violations, it-, is), *S/TROUGH (1 violation, it-), and *W/PEAK (1 violation, -self). Finally, one might expect a typical line of prose to be metrically more ambiguous and therefore allow more scansions than a typical line of verse because by definition prose lacks meter. Our informal observations support this conjecture, but substantiating it will be left for future work.

\section{The experiment}

In our experiment we used Prosodic to listen to differences between prose and verse. Our primary goal was to find out if there are systematic differences between prose and verse in terms of our constraints, and if so, what exactly those differences are. We also wanted to put H\&K's claim about the difference between mainstream English and Finnish meters to empirical test. Finally, the experiment was intended to serve as a reality check: if Prosodic were able to detect generalizations reported in earlier literature it would increase

\footnotetext{
${ }^{6}$ We also get a third scansion with a mixture of iambic and dactylic feet.

${ }^{7}$ For more examples, see Allen 2009. We are indebted to Stephanie Shaw for this reference.
} 
our confidence that our method is working and that it is worth pursuing further.

Our primary data consists of five-word text fragments with no punctuation. This means that any potential difference between prose and verse can only depend on the choice and linear arrangement of words. In our experiment we set the metrical parameters to allow exactly one syllable in a strong position and up to two syllables in a weak position. ${ }^{8}$ Constraint violation counts were normalized by dividing the sum of violations by the number of scansions and the number of syllables in the line.

5.1 Preliminary visualization We start by displaying the mean violation scores for all four phonological constraints by author. The English-language data are shown in (14); the Finnish-language data are shown in (15). It is important to keep in mind that these are just raw means that ignore all the other constraints that also contribute to shaping the data quantitatively.

English: Mean violation scores of phonological constraints
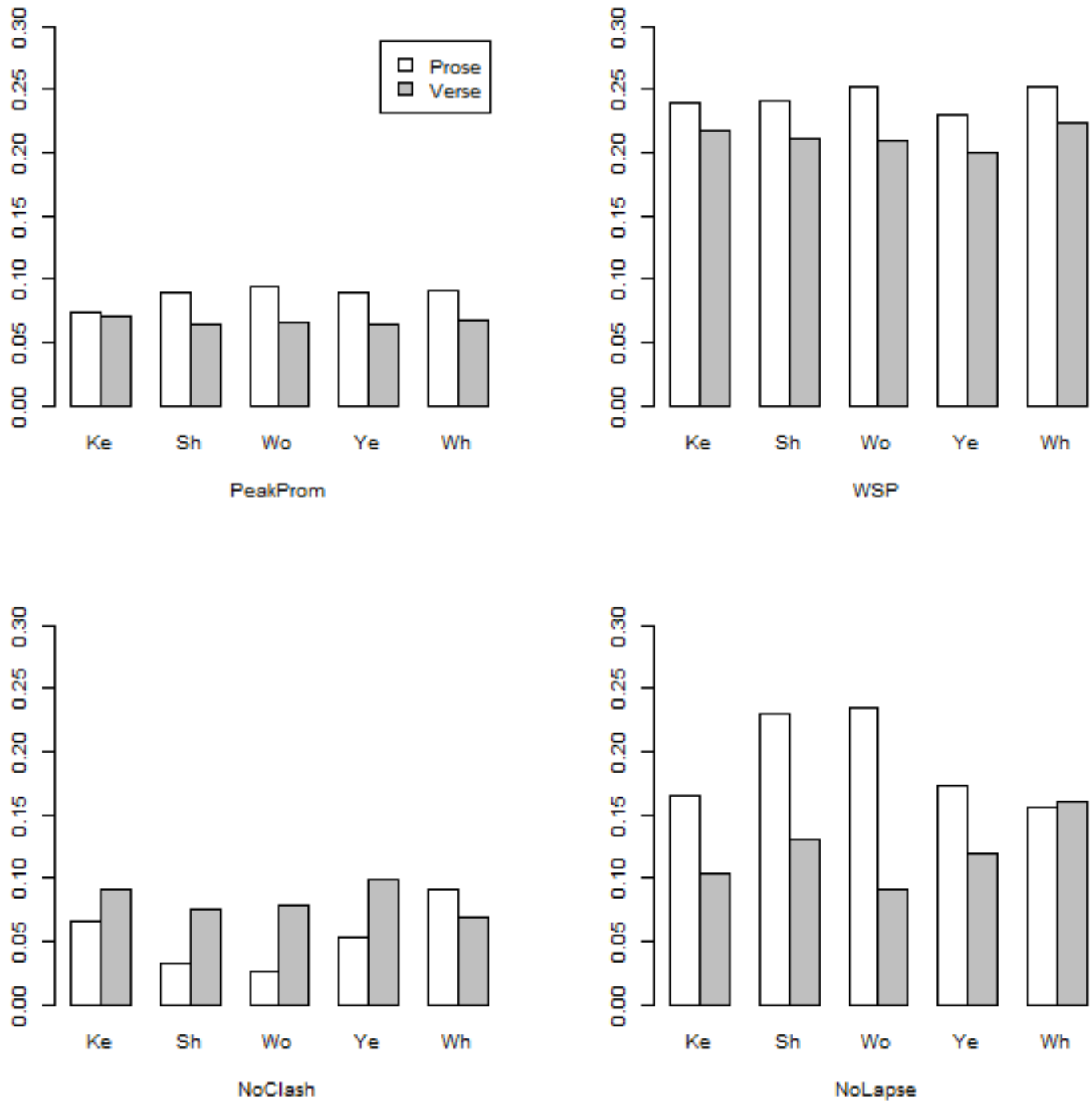

\footnotetext{
${ }^{8}$ We also experimented with a stricter setting that allowed only one syllable per position, but found the results uninterpretable.
} 
The picture shows that the English-language authors violate PEAKPROM, WSP, and NOLAPSE less in verse than in prose, suggesting that verse is phonologically less marked than prose. However, NOCLASH shows the opposite pattern. The one author who stands out as different is Whitman whose NOCLASH and NOLAPSE violation patterns are reversed, perhaps suggesting that his free verse scans like prose.

Finnish: Mean violation scores of phonological constraints
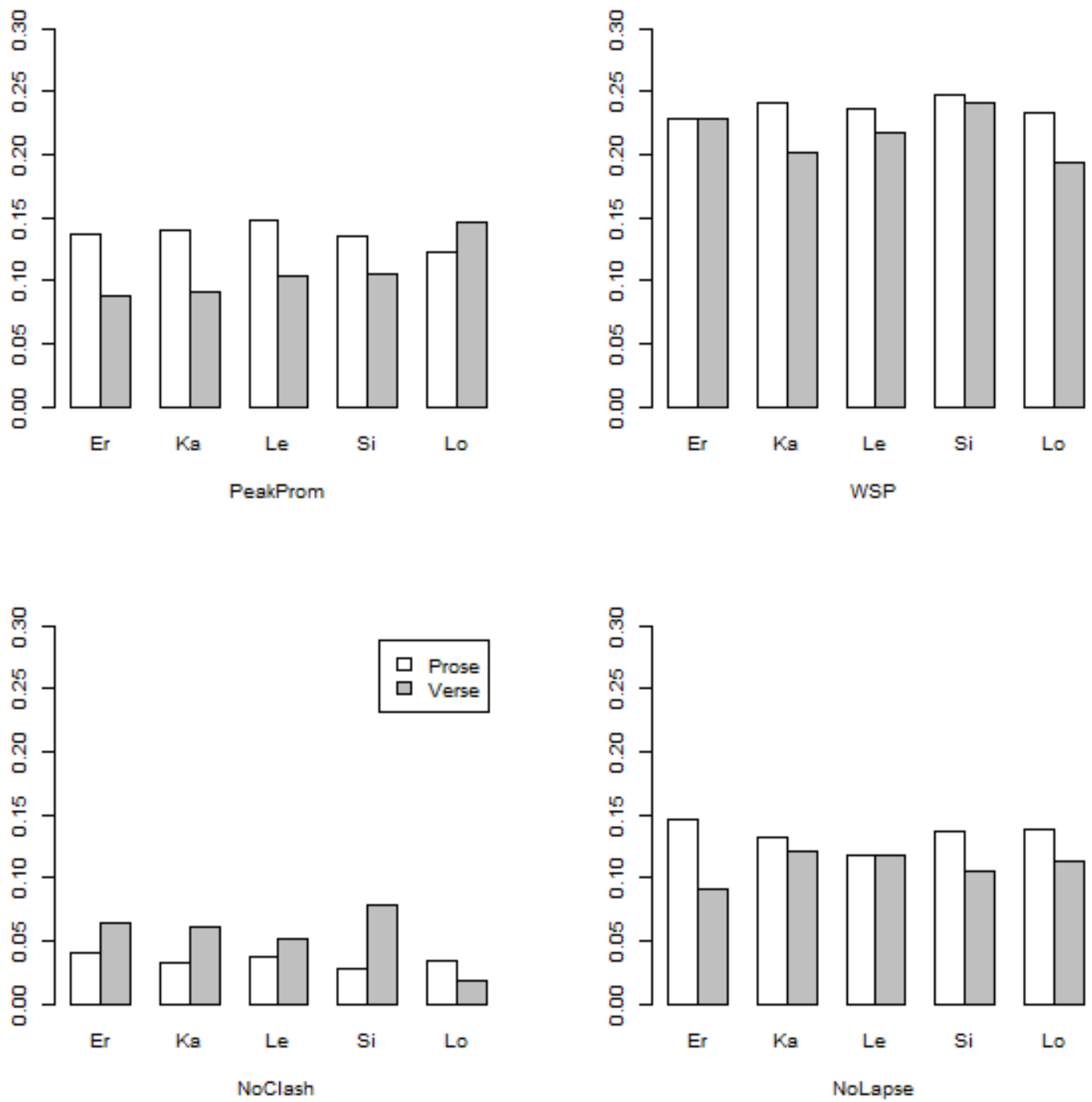

The Finnish picture is quite similar. Again, PEAKProm, WSP, and NOLAPSE are violated less in verse than in prose, and again, NOCLASH shows the opposite pattern. The one author who stands out as different is Lönnrot whose PEAKPROM and NOCLASH violation patterns are out of line with the rest. It is probably relevant that the Lönnrot verse actually comes from the Kalevala which is written in a very different meter. The higher incidence of PEAKPROM violations suggests that stressed lights are favored in the Kalevala and indeed the meter specifically refers to them: the fundamental rule defining the Kalevala meter is that stressed syllables must be heavy in strong positions, but light in weak positions (Kiparsky 1968, Ryan 2011).

The above constraints are all purely phonological. As for metrical constraints, looking at mean violations turns out not to be helpful. To examine their effect we will instead turn to regression modeling.

5.2 Regression modeling In order to understand the data better we modeled it using mixed-effects logistic regression (Bates et al. 2014). The key advantage of regression modeling is that it allows us to 
consider several predictors at once. Our dependent variable is genre (prose vs. verse); the independent variables (predictors) are the constraint violations, normalized and centered. In order to control for potential differences among the authors we included author in the model as a random variable. Only 6 constraints (4 phonological, 2 metrical) were included in the final model. The tables in (16) and (17) below summarize the key results. Model summaries can be found in the Appendix.

On the phonological side, the hypothesis that verse is less marked than prose was confirmed for all but one constraint. While stressed light syllables (PEAKPROM), unstressed heavy syllables (WSP), and stress lapses (NOLAPSE) are indeed characteristic of prose, stress clashes (NOCLASH) are characteristic of verse. The same effect is found both in English and in Finnish.

Which violations predict which genre: phonological constraints

$\begin{array}{lll}\text { PEAKPROM } & \text { ENGLISH } & \text { FINNISH } \\ \text { WSP } & \text { prose } & \text { prose } \\ \text { NOLAPSE } & \text { prose } & \text { prose } \\ \text { NoCLASH } & \text { verse } & \text { verse }\end{array}$

What might explain this effect? Two hypotheses suggest themselves. The first has to do with syntax: it is possible that unstressed function words are more common in prose than in verse and serve to resolve stress clashes as well as create stress lapses (Lev Blumenfeld, p.c.). The second has to do with word choice: it seems that prose is characterized by longer words than verse and within-word lapses are more common than withinword clashes. Finnish allows within-word lapses, but virtually no within-word clashes, if we ignore compounds. English allows both, but not to the same extent: in our syllabified CMU dictionary about 22\% of the words contain at least one lapse (e.g., ábacus, ámateurism), but only about $9 \%$ contain at least one clash (e.g., àccèlerátion, àntìtáx). Thus, the phonological differences between prose and verse may depend partly on their different syntax, partly on their preference for words of different lengths. ${ }^{9}$ Separating withinword and across-word clashes would be an interesting next step (Jon Barnes, p.c.). We hope to return to this topic in future work.

On the metrical side, we find H\&K's claim about the key metrical difference between English and Finnish verse to be supported:

(17) Which violations predict which genre: metrical constraints

$\begin{array}{lll}\text { *W/PEAK }_{\text {* }} & \begin{array}{l}\text { ENGLISH } \\ \text { prose }\end{array} & \begin{array}{l}\text { FINNISH } \\ \text { (non-sig.) }\end{array} \\ \text { *S/UNSTRESSED }^{\text {verse }} & \text { prose }\end{array}$

English verse cares about peaks in weak positions, hence violations of *W/PEAK are highly predictive of prose $(p<0.001)$. Finnish verse cares about stress in strong positions, hence violations of *S/UNSTRESSED 'A strong position may not contain an unstressed syllable' are predictive of prose $(\mathrm{p}<0.05)$. The observation that violations of *S/UNSTRESSED are predictive of verse in English is puzzling and we have no explanation for it.

The fact that our machine analysis yields results that are consistent with a known metrical generalization reported in earlier work is encouraging and suggests that our method is on the right track and worth exploring further. However, we wish to emphasize that our results are preliminary and need to be replicated in future work. In particular, we do not know to what extent they depend on particular analytical decisions, some of which are discussed in the following section.

\footnotetext{
${ }^{9}$ The preference for short words in verse has a plausible metrical explanation: monosyllabic words are metrically versatile whereas long words are harder to fit into the meter, sometimes to the point of being unusable (H\&K, pp. 294-306).
} 


\section{Residual problems}

The problem of function word stress looms large in the prosodic analysis of English. In our current experiment we used the following two word lists. All these forms actually occurred in our sample.

(18) Unstressed words (48 lemmas): ah, am, an, and, are, be, been, bout, can, could, had, has, hast, hath, he, her, him, his, if, i'll, is, it, its, lest, may, my, of, or, she, should, so, the, their, them, there's, they, thine, though, to, us, was, we, were, while, would, yore, you, your

Stress-ambiguous words (119 lemmas): a, ad, age, all, art, as, at, back, but, by, can't, dare, de, di, did, die, do, does, done, don't, dost, down, each, few, for, force, from, grand, have, he'll, here, here's, how, i, i'd, in, i've, la, last, least, less, like, me, might, mine, mode, more, most, much, must, near, need, next, nor, o, off, on, one, one's, ought, out, pains, per, piece, place, pour, round, route, rue, sake, sang, save, say, shall, since, sit, sole, some, son, such, than, that, that's, thee, theirs, then, there, these, they'd, this, those, thou, through, thy, till, tout, up, we'll, we're, what, what's, when, whence, where, which, who, whom, whose, why, wil, will, wilt, with, ye, yet, you'd, you'll, you're, yours

These lists are based on the Brown corpus augmented by examples available from the AMALGAM web site at the University of Leeds (comp.leeds.ac.uk/ccalas/tagsets/brown.html). We first compiled a list of monosyllabic words that were not nouns, verbs, adjectives, or adverbs. The initial list contained 876 words. Foreign words (about every fifth word on the list) pose special problems. For example, it is not clear how the Latin $a d$ or sit or the French tout are stressed when they occur in English. These words are currently included on the stress-ambiguous list. Other ambiguities include art (noun vs. auxiliary) and save (verb vs. preposition). The word bout on the unstressed list is the reduced variant of about. Our final three-way taxonomy (unstressed, stress-ambiguous, stressed) was informed by the more fine-grained taxonomy of Hirschberg 1993. It should be obvious that these lists are just a first approximation and that further work is needed. For a novel corpus-based approach to function word classification, see Shih 2014.

Our annotation of English syllable weight is based on the following simple rules: (i) Syllables that are unambiguously closed by a consonant are heavy; (ii) Open syllables with a long vowel are heavy; (iii) Open syllables with a short vowel are light. Questions arise in words like city currently annotated as follows:

\section{CITY S IH1 T IY0 /\# [ S '1 IH ] [ T '0 IY ] \#/ S:PU W:LH}

The weight annotation of this word is currently LH. This involves two controversial decisions. First, assuming that the intervocalic $t$ is ambisyllabic (Kahn 1976) the first syllable should count as heavy. Second, the tense vowel in the second syllable seems to result from a late tensing rule that varies across dialects and the vowel does not count as long (Halle and Mohanan 1985), hence the second syllable should count as light. Another issue involves the weight of word-final syllables which depends on whether final consonants are analyzed as extrametrical (Hayes 1982). In our experiment we ignored this complication and treated all word positions the same. Analytical issues like this are important because they decide whether constraints like PEAKPROM 'No stressed light syllables' and WSP 'No unstressed heavy syllables' are violated or not. Finding principled solutions to problems of this sort is left fur future research.

In Finnish, the remaining analytical problems often involve variable secondary stress (see, e.g., Anttila 2012). One aspect of this problem is the variable syllabification of non-initial vowel sequences where the second vowel is [+high, +round], as in rák.ka.ù.den rák.kau.den 'love-GEN', láu.ka.ùs.ta láu.kaus.ta 'shot-PAR' (Häkkinen 1978:26, Anttila and Shapiro, in progress). Only one variant is currently predicted.

\section{Conclusion}

The evidence examined in this paper suggests that prose and verse differ, not only metrically, but also phonologically. On the general level this may not be very surprising: we have found that knowledge of meter guides the author (consciously or subconsciously) in making linguistic choices. However, the specifics merit a close look. The constraint violations we have discussed depend on two kinds of choices: which words to 
use (a paradigmatic choice) and how to order them (a syntagmatic choice) (Anttila 2016). The violations of PEAKPROM 'No stressed light syllables' and WSP 'No unstressed heavy syllables' arise within a single word, so their presence or absence is purely a matter of word choice. We can thus conclude that words with such marked syllable types are avoided in verse more than in prose. In contrast, violations of NoCLASH 'No adjacent stressed syllables' and NOLAPSE 'No adjacent unstressed syllables' may arise either as a result of word choice or as a result of combining words. Separating within-word and across-word violations would allow us to study whether both types of effects are real. Finally, verse and prose are not homogeneous genres: iambic verse is not dactylic verse and oratorical prose is not newswire. Exploring such differences is a project left for future work.

\section{Appendix}

Regression model summaries are shown below. Only 6 constraints (4 phonological, 2 metrical) were included in the final model. Positive estimate means the predictor favors prose. Predictors that significantly favor verse are highlighted in bold. Predictor labels: strength.w.not.p.norm $={ }^{*} \mathrm{~W} / \mathrm{PEAK}$ (normalized and centered); stress.s.not.u.norm $={ }^{*}$ S/UNSTRESSED (normalized and centered).

English:

\begin{tabular}{|c|c|c|c|c|c|}
\hline $\begin{array}{l}\text { Groups Name } \\
\text { author (Intercept) }\end{array}$ & \multicolumn{2}{|c|}{$\begin{array}{l}\text { Variance Std.Dev. } \\
0.0016420 .04053\end{array}$} & & & \\
\hline Number of obs: 4998 , & groups: a & athor, 5 & & & \\
\hline \multicolumn{6}{|l|}{ Fixed effects: } \\
\hline & Estimate & Std. Error & z value & $\operatorname{Pr}(>|z|)$ & \\
\hline (Intercept) & -0.09753 & 0.03524 & -2.767 & 0.005653 & $\star \star$ \\
\hline PeakProm.norm & 2.08197 & 0.34400 & 6.052 & $1.43 e-09$ & $\star \star \star$ \\
\hline WSP.norm & 0.76774 & 0.24317 & 3.157 & 0.001593 & $\star \star$ \\
\hline NoClash. norm & -1.04892 & 0.29093 & -3.605 & 0.000312 & $\star \star \star$ \\
\hline NoLapse.norm & 5.51223 & 0.34643 & 15.911 & $<2 e-16$ & $\star \star \star$ \\
\hline strength.w.not.p.norm & 3.89682 & 1.02836 & 3.789 & 0.000151 & $\star \star \star$ \\
\hline stress.s.not.u.norm & -4.99258 & 0.81991 & -6.089 & $1.14 e-09$ & $\star \star \star$ \\
\hline
\end{tabular}

Finnish:

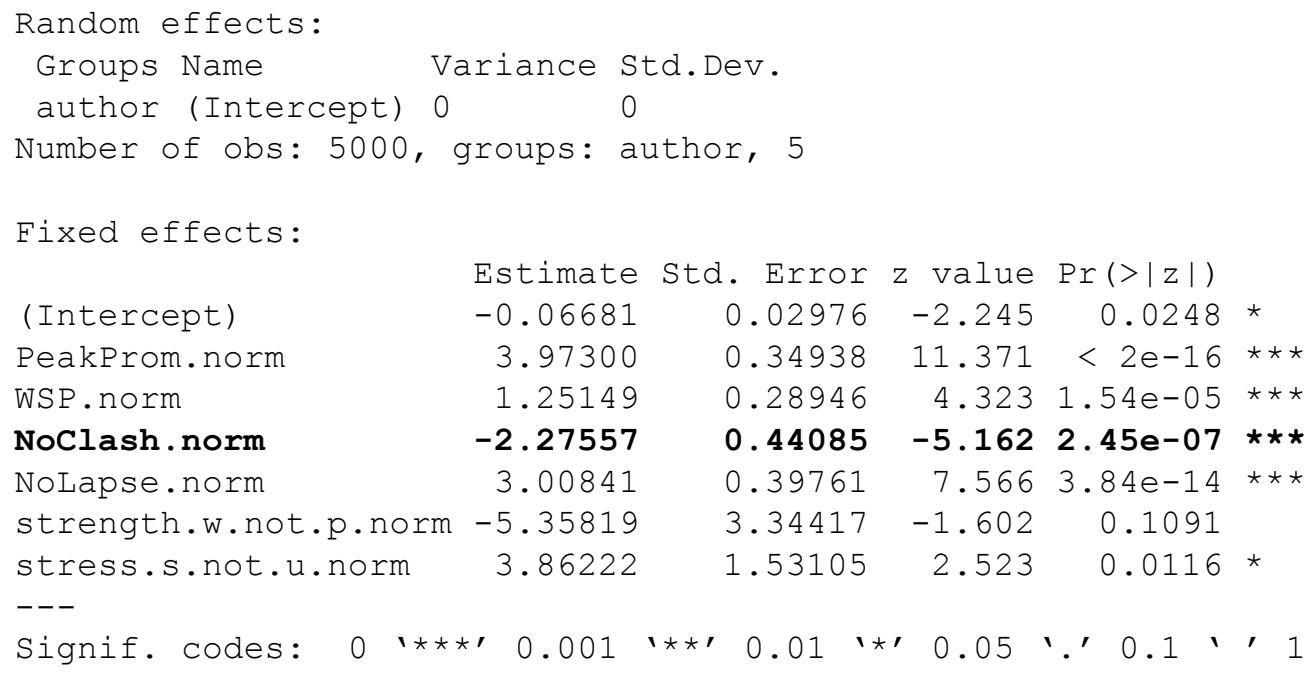




\section{References}

Allen, Henry. 2009. His way with words: Cadence and credibility, The Washington Post, January 20, 2009, pp. AA2325. washingtonpost.com/wp-dyn/content/article/2009/01/17/AR2009011701429.html.

Anttila, Arto. 2012. Modeling phonological variation. In Abigail C. Cohn, Cécile Fougeron, and Marie Huffman (eds), The Oxford Handbook of Laboratory Phonology, Oxford University Press, Oxford, pp. 76-91.

Anttila, Arto. 2016. Phonological effects on syntactic variation, Annual Review of Linguistics 2, 115-137.

Anttila, Arto and Naomi Shapiro. in progress. The interaction of stress and syllabification: parallel or serial? Ms., Stanford University.

Bates, Douglas, Martin Maechler, Ben Bolker and Steven Walker. 2014. lme4: Linear mixed-effects models using Eigen and S4. R package version 1.1-6. CRAN.R-project.org/package=lme4.

Blumenfeld, Lev. 2015. Meter as faithfulness, Natural Language and Linguistic Theory, 33(1), 79-125.

Golston, Chris. 1998. Constraint-based metrics, Natural Language and Linguistic Theory 16(4), 719-770.

Golston, Chris, and Tomas Riad. 2000. The phonology of classical Greek meter. Linguistics 38(1), 99-167.

Golston, Chris, and Tomas Riad. 2005. The phonology of Greek lyric meter. Journal of Linguistics 41(1), 77-115.

Häkkinen, Kaisa. 1978. Suomen yleiskíelen tavuttamisesta [On the syllabification of standard Finnish], in Rakenteita: Juhlakirja Osmo Ikolan 60-vuotispäiväksi 6.2.1978, Publications of the Department of Finnish and General Linguistics of the University of Turku 6.

Halle, Morris, and K. P. Mohanan. 1985. Segmental phonology of modern English. Linguistic Inquiry 16(1), 57-116.

Hanson, Kristin and Paul Kiparsky. 1996. A parametric theory of poetic meter, Language 72(2), 287-335.

Hayes, Bruce. 1982. Extrametricality and English stress, Linguistic Inquiry 13(2), 227-276.

Hayes, Bruce, Colin Wilson and Anne Shisko. 2012. Maxent grammars for the metrics of Shakespeare and Milton, Language 88(4), 691-731.

Heuser, Ryan, Joshua Falk, and Arto Anttila. 2010. Prosodic (software), Stanford University, github.com/quadrismegistus/prosodic.

Hirschberg, Julia. 1993. Pitch accent in context: predicting intonational prominence from text, Artificial Intelligence 63(1), 305-340.

Kahn, Daniel. 1976/2015. Syllable-based generalizations in English phonology. Routledge, Oxford and New York.

Karlsson, Fred. 1982. Suomen kielen äänne- ja muotorakenne [The Phonological and Morphological Structure of Finnish], Werner Söderström Osakeyhtiö, Helsinki.

Karlsson. Fred. 1985. Automatic hyphenation of Finnish, in Computational Morphosyntax: Report on Research 1981 1984, Publication no. 13, University of Helsinki, Department of General Linguistics, pp. 93-113. ling.helsinki.fi/ fkarlsso/Automatic_hyphenation.PDF

Kiparsky, Paul. 1968. Metrics and morphophonemics in the Kalevala, in Studies presented to Professor Roman Jakobson by his students. Reprinted in Donald C. Freeman (1970, ed.), Linguistics and Literary Style, Holt, Rinehart and Winston, Inc., New York, pp. 195-181.

Kiparsky, Paul. 1977. The Rhythmic Structure of English Verse, Linguistic Inquiry 8(2), 189-247.

Kiparsky, Paul. 1989. Sprung rhythm, in Paul Kiparsky and Gilbert Youmans (eds), Phonetics and Phonology I: Rhythm and Meter, San Diego: Academic Press, pp. 305-340.

McCarthy, John J. 2008. Doing Optimality Theory, Blackwell Publishing, Malden, Massachusetts.

Prince, Alan. 1989. Metrical forms, in Paul Kiparsky and Gilbert Youmans (eds), Phonetics and Phonology I: Rhythm and Meter, Academic Press, San Diego, pp. 45-80.

Prince, Alan. 1990. Quantitative consequences of rhythmic organization, in M. Ziolkowski, M. Noske, K. Deaton (eds), Papers from the Chicago Linguistic Society 26(2), pp. 355-398.

Prince, Alan and Paul Smolensky 1993/2004. Optimality Theory: Constraint Interaction in Generative Grammar, Blackwell Publishing, Malden, Massachusetts.

Ryan, Kevin M. 2011. Gradient syllable weight and weight universals in quantitative metrics, Phonology 28(3), 413-454. Shih, Stephanie. 2014. Towards Optimal Rhythm, PhD thesis, Department of Linguistics, Stanford University.

Steele, Timothy. 1999. All the Fun's in How You Say a Thing, Ohio University Press, Athens.

Weide, R. L. 1998. The CMU Pronouncing Dictionary, release 0.6 [syllabification, stress, and weight annotation added by Michael Speriosu], http://web.stanford.edu/ anttila/research/sylcmu.txt.

Email: anttila@stanford.edu,heuser@stanford.edu 